\title{
Parenting styles of abusive mothers in group-living rhesus macaques
}

\author{
DARIO MAESTRIPIER I \\ D epartment of P sychology and $Y$ erkes $R$ egional P rimate R esearch C enter, E mory U niversity
}

( Received 23 September 1996; initial acceptance 23 J anuary 1997;

final acceptance 20 February 1997; M S. number: A7712)

\begin{abstract}
A bstract. $M$ aternal abuse of offspring in group-living monkeys was investigated to assess whether abuse of infants can be interpreted as an adaptive reduction of parental expenditure or as a behavioural pathology. I compared the parenting styles of 10 abusive and 10 non-abusive rhesus macaque, $M$ acaca mulatta, mothers living in three large captive groups over the first 12 weeks of infant life. I also analysed the social interactions between mothers and infants and other individuals. A busive females scored higher than controls on several measures of maternal protectiveness and rejection, indicating that they were highly controlling mothers. They also received fewer contacts and approaches from other individuals, and tended to be more aggressive and more interested in other females' infants compared to non-abusive mothers. Infant abuse was accompanied by similar or higher parental expenditure in the offspring rather than by a reduction in expenditure, as predicted by the adaptive hypothesis. Therefore, the results of this study support the hypothesis that infant abuse is a form of behavioural pathology. Infant abuse in rhesus macaques shows parallels with that in other primate species, but some of its characteristics could be a by-product of species-specific behavioural adaptations of rhesus macaques.

(C) 1998 The Association for the Study of A nimal Behaviour
\end{abstract}

Parental care can be defined as any parental behaviour that appears likely to increase the fitness of a parent's offspring (Clutton-Brock 1991). Most of the behaviour that a parent shows towards her offspring during the period of offspring dependence falls within the range of parental care. The expenditure of energy, time and other parental resources in the care of the offspring, however, may vary among individuals of the same species or within an individual's lifetime, because parents are selected to maximize the difference between the benefits of care to their offspring and its costs to themselves (W illiams 1966; Trivers 1972; Winkler 1987). When the costs of parental care outweigh its benefits, parents are expected to reduce or terminate their expenditure in their offspring, even if the offspring are still dependent on them. This may occur, for example, when the certainty of parenthood is low, when parental resources are limited or when the offspring's chances of survival are reduced (CluttonBrock 1991).

Correspondence: D. M aestripieri, Y erkes R egional Primate Research Center, Emory University, 2409 Taylor Lane, Lawrenceville, GA 30243, U.S.A. (email: psydm@emory.edu).
When the conditions favouring early termination of parental expenditure occur, the parent's behaviour toward the offspring may fall outside the definition of parental care and include neglect, abandonment, abuse, infanticide or cannibalism. Early reduction or termination of parental expenditure in response to circumstances unfavourable to reproduction has been reported in animal taxa from insects to primates, including humans (e.g. Bernds \& Barash 1979; H aig 1990; M aestripieri 1991; F airbanks \& M cG uire 1995).

Behavioural phenomena such as parental neglect, abuse or cannibalism of the offspring, however, may also result from genetic abnormalities (e.g. Brown et al. 1996) or reflect environment-induced pathologies (e.g. A rling \& Harlow 1967). Although maladaptive animal behaviour is often the result of human manipulations, some behavioural pathologies are also expected to occur among animals living in natural environments with minimal human influence. U nderstanding causes of maladaptive behaviour can provide insight into the mechanisms underlying the regulation of adaptive behaviour.

One issue relevant to both functional and mechanistic studies of behaviour is how to 
distinguish adaptations from pathologies. The most direct approach to the problem, that is the assessment of the relative balance of fitness costs and benefits of the behaviour in question, is not always feasible. F or example, an accurate assessment of lifetime reproductive success is a problem when studying animals with a long life span, or who, like humans, live in an environment that is very different from the one in which they evolved.

A $n$ accurate observation and analysis of behaviour can be a profitable alternative strategy. For example, if reduction of expenditure in one parental activity, such as feeding the young, reflects an adaptive pattern of reduced parental investment, one should expect a consistent reduction of expenditure across all parental activities, across contexts and over a certain period. In contrast, if parents decrease their expenditure in one caregiving activity and in some contexts but not in others, and if changes in their behaviour are unpredictable and independent of changes in the environment (e.g. parents rapidly alternate between high and low parental expenditure during environmental stability), then their behaviour is likely to be maladaptive.

In the present study, I applied this behavioural approach to a study of maternal abuse of offspring in group-living rhesus macaques, $\mathrm{M}$ acaca mulatta. M aternal abuse of offspring was first reported by $\mathrm{H}$ arlow and co-workers in laboratory-raised rhesus monkeys and consisted of infant dragging, pulling, hitting or biting (Harlow \& Seay 1966; A rling \& Harlow 1967). The abusive mothers observed by $\mathrm{H}$ arlow also showed abnormal behaviour in social contexts including communication, mating, affiliation and aggression; these abnormalities were probably induced by human experimental manipulations such as early separation of infants from their mothers and rearing in conditions of severe social deprivation.

$M$ aternal abuse of offspring has also been observed among macaques living in relatively undisturbed social groups in captivity and in the wild (H iraiwa 1981; Troisi et al. 1982; Maestripieri 1994a). A part from a few welldocumented cases, no systematic investigation of infant abuse has been conducted in unmanipulated social groups, in part due to the low fre quency of occurrence of this phenomenon in group-living monkeys. Three recent epidemiological and multi-generational studies of infant abuse in rhesus macaques, pigtail macaques, $M$. nemestrina, and sooty mangabeys, Cercocebus atys, showed that only about $10 \%$ of mothers physically abuse their infants ( $M$ aestripieri \& Carroll, in press a, M aestripieri et al. 1997, in press).

In macaque groups where infant abuse was observed, human manipulations were minimal or non-existent, and abusive mothers were otherwise socially skilful individuals. Therefore, a question arises as to whether infant abuse can be understood within the framework of parental investment theory or whether it reflects a naturally-occurring pathology specific to the care-giving domain. To address this question, I investigated the parenting styles of abusive rhesus mothers living in relatively undisturbed social groups. I compared abusive and non-abusive mothers in their styles of interaction with their infants over the first 12 weeks of infant life. I also investigated social interactions between mothers and infants and other individuals. The adaptive hypothesis views infant abuse as a form of reduction or termination of parental expenditure ( $D$ aly \& Wilson 1981) and predicts that infant abuse should also be accompanied by reduced expenditure in other parental activities, across contexts and with consistency over time. In contrast, the pathology hypothesis predicts no necessary consistency between infant abuse and reduced expenditure in other parental activities, across contexts or over time.

\section{METHODS}

\section{Subjects and Procedure}

At the beginning of the rhesus birth season (M arch 1996) I began ad libitum observations of four rhesus macaque groups (A 1, A 2, A 3, A4) housed in adjacent outdoor compounds $(25 \times 25 \mathrm{~m})$ with attached indoor quarters at the Field Station of the $Y$ erkes Regional Primate Research Center in Lawrenceville, Georgia, U.S.A. Each of the four groups consisted of two to five adult males and 25-30 adult females with their subadult and juvenile offspring.

The criterion used to identify abusive mothers was the occurrence of one of the following behaviour patterns: infant dragging, crushing, throwing or sitting/stepping on. These are the most commonly observed patterns of infant abuse in macaques (Troisi \& D 'A mato 1983; M aestripieri 
Table I. Socio-demographic characteristics of abusive and control mother-infant pairs

\begin{tabular}{|c|c|c|c|c|c|}
\hline M others & R ank & A ge (years) & Parity & $\begin{array}{l}\% \text { Previous } \\
\text { offspring } \\
\text { surviving first } \\
6 \text { months }\end{array}$ & Infant sex \\
\hline \multicolumn{6}{|l|}{ A busive } \\
\hline $\mathrm{RAj}$ & $M$ & 5 & $M$ & 100 & M \\
\hline $\mathrm{RDe}$ & $\mathrm{L}$ & 5 & $M$ & 0 & $M$ \\
\hline $\mathrm{RDh}$ & $\bar{M}$ & 11 & $M$ & 67 & $\mathrm{~F}$ \\
\hline $\mathrm{REa}$ & $\mathrm{L}$ & 4 & $P$ & - & $M$ \\
\hline RFy & $\bar{M}$ & 9 & $M$ & 60 & $\mathrm{~F}$ \\
\hline $\mathrm{RNj}$ & $\mathrm{L}$ & 11 & $M$ & 80 & $\mathrm{~F}$ \\
\hline ROi & $\mathrm{H}$ & 5 & $M$ & 0 & $M$ \\
\hline RTp & $\mathrm{H}$ & 4 & $M$ & 0 & $M$ \\
\hline$R Y d$ & $\mathrm{H}$ & 12 & $M$ & 100 & $\mathrm{~F}$ \\
\hline $\mathrm{RZq}$ & $M$ & 4 & $P$ & - & $M$ \\
\hline \multicolumn{6}{|l|}{ Controls } \\
\hline $\mathrm{RCg}$ & $M$ & 5 & $P$ & - & $M$ \\
\hline RDj & $M$ & 4 & $P$ & - & $\mathrm{F}$ \\
\hline$R G b$ & $\mathrm{H}$ & 5 & $M$ & 100 & $\mathrm{~F}$ \\
\hline $\mathrm{RHO}$ & $M$ & 7 & $M$ & 100 & $M$ \\
\hline RJe & $\mathrm{H}$ & 9 & $M$ & 100 & $M$ \\
\hline ROd & $\mathrm{L}$ & 9 & $M$ & 100 & $M$ \\
\hline $\mathrm{RPe}$ & $\mathrm{M}$ & 4 & $P$ & - & $\mathrm{F}$ \\
\hline R Sh & $M$ & 8 & $M$ & 67 & $\mathrm{~F}$ \\
\hline RUm & $\mathrm{L}$ & 7 & $M$ & 67 & $M$ \\
\hline $\mathrm{RVi}$ & $\mathrm{L}$ & 8 & $M$ & 100 & $M$ \\
\hline
\end{tabular}

Rank: $\mathrm{H}=$ high, $\mathrm{M}=$ middle, $\mathrm{L}=$ low.

Parity: $P=$ primiparous, $M=$ multiparous.

Infant sex: $M=$ male, $F=$ female.

1994a; M aestripieri et al. 1997). These patterns are also distinguishable from other behaviours in the maternal and aggressive repertoire, such as those observed during mother-infant weaning conflicts. Because other abuse patterns such as hitting and biting sometimes occur during mother-infant weaning conflicts, they were not used for the initial identification of abusive mothers. I identified 10 abusive mothers: one in the $A 1$ group, six in the $A 3$ group and three in the A 4 group (Table I). In seven of these mothers, the first episode of infant abuse was observed in the first week of infant life. In the other three mothers, the first infant abuse episode was observed in weeks 5, 7 and 9, respectively.

A s soon as I observed the first episode of infant abuse, I began focal observations ( $M$ artin \& Bateson 1986) of the mother and her infant and continued them until the 12th week of infant life. I observed each mother-infant pair for $30 \mathrm{~min}$ four times each week, randomly between 0800 and 1900 hours. I made observations from a platform that provided an unrestricted view of the entire compound and collected data with a portable computer.

Ten rhesus mothers whom I never observed infant dragging, crushing, throwing or sitting/ stepping on in the first 12 weeks of infant life served as controls (Table I). A ll controls belonged to the A 4 group and were observed during the birth season of 1993 (M aestripieri 1994b, c). The 1993 study comprised 11 mothers, but one of them displayed infant dragging once, and therefore was not used as a control. A lthough the subjects and controls were observed in different years, size and composition of all four rhesus groups has remained stable over the years, and subjects and controls had similar characteristics and history. All mothers were born and raised by their biological mothers in the groups in which they were observed. Prior to this study, they had been used mostly for breeding purposes and observational studies of behaviour, and had never been used for invasive experimental studies or removed from 
their social group for long periods other than for medical reasons. Among the abusive mothers, there was one mother with two adult daughters (RDh, RAj, RZq) and a mother-daughter pair ( $R \mathrm{Nj}, \mathrm{RD}$ e). A mong non-abusive mothers, there was one mother-daughter pair (RJe, RGb) and one mother-niece pair (ROd, RVi). One abusive and one non-abusive mother ( $\mathrm{ROi}, \mathrm{RCg}$ ) were sisters. I observed abusive mothers and controls with identical procedures and for the same period of infant life. A busive subjects were observed for 204 hours; controls were observed for 240 hours.

\section{B ehavioural 0 bservations}

$D$ ata collection included infant abuse and other interactions between mothers and infants, between mothers and other individuals and between infants and other individuals (see also M aestripieri 1994b, c).

Infant abuse

The following maternal behaviour patterns were included in the infant abuse category: (1) dragging: the mother drags her infant by its tail or leg while walking or running; (2) crushing: the mother pushes her infant against the ground with both hands; (3) throwing: the mother throws her infant at a short distance with one hand while standing or walking; (4) hitting: the mother violently slaps her infant with one hand or arm; (5) biting; (6) stepping or sitting on: the mother steps on her infant with one foot or both feet, or sits on her infant; (7) dangling/dropping: the mother climbs a tree or fence and holds her infant by its tail or leg or drops her infant on the ground; (8) rough grooming: the mother pulls her infant's hair or otherwise roughly grooms it causing distress calls; (9) stretching: the mother holds her infant by its arms and/or legs and stretches it; (10) somersaulting: the mother runs and somersaults with her infant clinging to her chest. Infant abuse was scored independently of all the other motherinfant interactions (e.g. rejection).

A buse events did not last more than a few seconds, so I recorded only their frequency. I recorded infant abuse as two separate events if there was a transition in the pattern of behaviour (e.g. from dragging to throwing) or if there was a pause of at least $10 \mathrm{~s}$ during the behaviour. A buse bouts consisted of single abuse events or of two or more events that occurred within $30 \mathrm{~s}$ of each other.
$M$ other-infant interactions

I used the following measures: (1) percentage of time spent in contact; (2) frequency of contacts made and broken by mothers and infants; (3) frequency of approaches and leaves by mothers and infants (scored in relation to the proximity within arm's reach, about $60 \mathrm{~cm}$ ); (4) percentage of all infant attempts to break contact that were prevented by the mother by pulling the infant by its tail or leg (restraining); (5) percentage of all infant attempts to make contact that were prevented by the mother by turning, running away or holding the infant at a distance with an arm (rejection); (6) percentage of contact time in which the mother kept her arms around the infant (cradling); (7) percentage of contact time in which the mother groomed her infant. The rate at which mothers scratched themselves (number of episodes per $1000 \mathrm{~s}$ ) when their infants were out of contact was used as an indicator of maternal anxiety (M aestripieri et al. 1992; M aestripieri 1993a, b).

\section{$M$ other- others interactions}

I used the following measures: (1) frequency of contacts made and received by mothers; (2) frequency of approaches made and received by mothers (in relation to the proximity within arm's reach); (3) frequency and duration of grooming done and received by mothers; (4) frequency of aggressive acts (threats, bites, and chases) done and received by mothers; (5) frequency of infant handling (touching, grooming, harassing) episodes initiated by mothers with infants other than their own.

\section{Infant-others interactions}

I used the following measures: (1) frequency of infant handling (touching, carrying) episodes initiated by other individuals; (2) duration of grooming received by infants; (3) frequency of infant harassment (pulling, dragging, hitting, biting associated with infant screams) episodes initiated by other individuals. I also recorded the frequency of infant scream vocalizations.

\section{D ata Analysis}

I used chi-square tests to compare the dominance rank and parity of abusive mothers and controls and the sex of their infants. $M$ aternal age 
and previous offspring survival were compared with t-tests for unpaired samples. The frequencies and durations of behaviour recorded in the four weekly sessions were summed to obtain weekly scores and then analysed in 4-week blocks with repeated measures ANOVA (factors: subjects/ controls and infant age) followed by BonferroniDunn post hoc tests. The number of abusive subjects used for the analyses was seven, nine, and 10 in the first, second and third month, respectively. Whenever the data failed to meet the assumptions necessary for the use of parametric tests, they were transformed by using squareroot transformations in case of frequencies and durations, and arcsine transformations for percentages. Probabilities $\leq 0.05$ were considered significant.

\section{RESULTS}

A busive mother-infant pairs did not differ significantly from control pairs in the maternal dominance rank $\left(\chi_{2}^{2}=0.31, P>0.05\right)$, parity $\left(\chi_{1}^{2}=0.27\right.$, $P>0.05)$, age $\left(t_{18}=0.33, P>0.05\right)$, or infant sex $\left(\chi_{1}^{2}=0, P>0.05\right.$; Table I $)$. The percentage of pre vious offspring that survived the first 6 months of life was significantly lower for abusive mothers than for controls $\left(\mathrm{t}_{13}=-2.23, \mathrm{P}<0.05\right)$.

Infant dragging was the most frequent infant abuse pattern, followed by crushing, throwing, biting, hitting and stepping/sitting on the infant (Fig. 1a). Other less frequent patterns accounted for about $10 \%$ of all abuse events. Infant abuse events and bouts were most frequent in the first week of life, when infants were abused with an average rate of about four events/h, and decreased thereafter ( $\mathrm{Fig} . \mathrm{Ib}$ ). A buse bouts consisted of up to four events. Infant abuse caused infant distress calls ( $F$ ig. $1 b$ ) but was never as severe as to require intervention for medical treatment. Control mothers induced few distress calls in their infants.

Infant abuse events were accompanied by considerable agitation in the group. Juvenile and adult females often approached the abusive mother and her infant and attempted to touch and retrieve the screaming infant. In some of the most dramatic episodes of abuse, the alpha male approached and mounted the abusive mother.

\section{M other-Infant Interactions}

A busive mother-infant pairs spent more time in contact than controls in the second $\left(F_{1,16}=7.48\right.$,

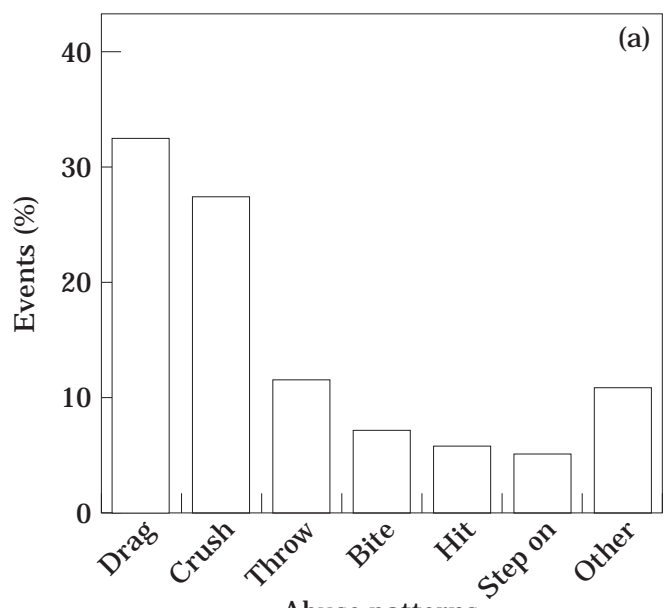

Abuse patterns

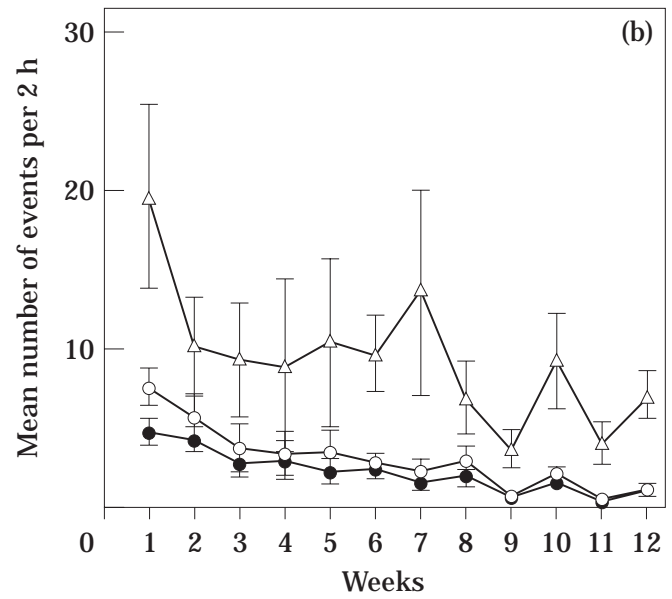

Figure 1. (a) Percentage of occurrence of different abuse patterns; (b) mean \pm SE number of infant abuse events $(-\bigcirc-)$, and bouts $(-\mathbf{0}-)$, and infant distress calls $(-\triangle-)$ of abused infants per individual per week.

$P<0.05)$ and in the third month of infant life $\left(F_{1,18}=24.94, P<0.0001 ; F i g .2 a\right)$. In the first 4 weeks of life, time in contact decreased linearly in controls but not in abusive mother-infant pairs $\left(F_{3,45}=3.47, P<0.05\right)$. There were no significant differences in maternal cradling and grooming between subjects and controls (Fig. $2 b, c$ ).

A busive mothers broke more contacts with their infants than controls in the second month $\left(F_{1,16}=4.49, P=0.05\right)$, but had fewer leaves in the third month $\left(F_{1,18}=5.72, P<0.05 ; F\right.$ ig. $\left.3 a, b\right)$. In the first month, the number of leaves increased sharply for abusive mothers but not for control mothers $\left(F_{3,45}=4.26, P<0.01\right)$. A bused infants 

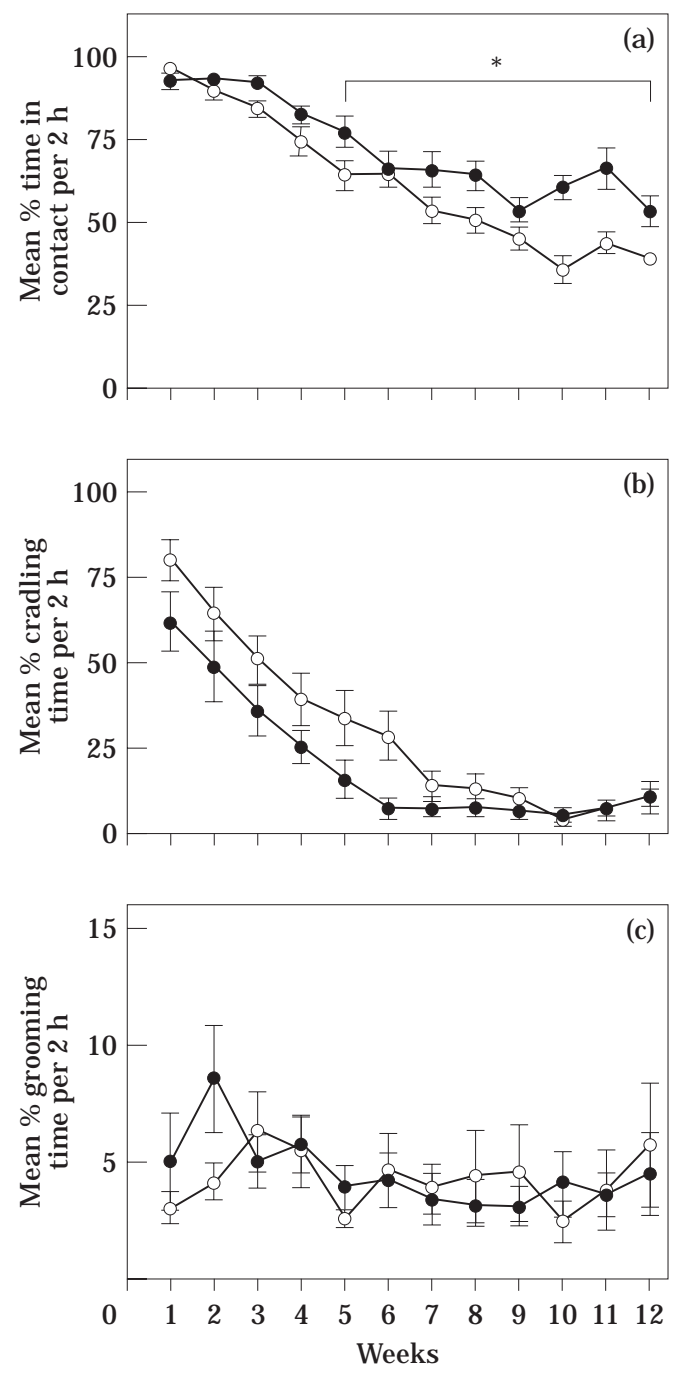

Figure 2. (a) $M$ ean \pm SE percentage of time spent in mother-infant contact in subjects $(--)$ ) and controls $(-\bigcirc-)$ per individual per week. Differences are significant in the second and third month of infant life $\left({ }^{*}\right)$; (b) mean \pm SE percentage of contact time spent in cradling in subjects and controls per individual per week; (c) mean \pm se percentage of contact time spent in grooming in subjects and controls per individual per week.

attempted to break contact less frequently than controls in the second month $\left(F_{1,16}=6.28\right.$, $P<0.05)$, but their frequency of leaving was not significantly different (Fig. $4 a, b$ ). A busive mothers initiated a higher percentage of contacts with and approaches to their infants than controls
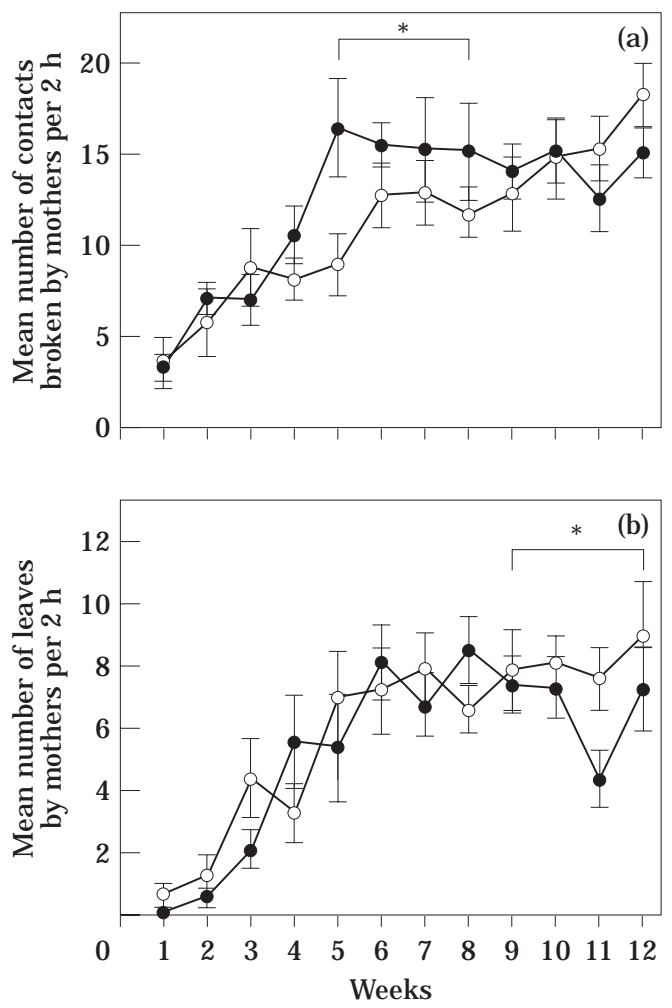

Figure 3. (a) $M$ ean \pm SE number of contacts broken by abusive (- -$)$ and control $(-\bigcirc-)$ mothers per individual per week. Differences are significant in the second month of infant life $(*)$; (b) mean \pm se number of leaves by abusive and control mothers per individual per week. Differences are significant in the third month of infant life $(*)$.

in the third month (contacts: $F_{1,18}=6.52, P<0.05$; approaches: $F_{1,18}=7.01, P<0.05$; $F$ ig. $\left.5 a, b\right)$.

A busive mothers restrained their infants more than did controls in the second $\left(F_{1,16}=4.48\right.$, $P=0.05)$ and third month $\left(F_{1,18}=9.90, P<0.01\right.$; Fig. 6a). Abusive mothers also rejected their infants more than did controls in all three months (first month: $F_{1,5}=11.15, P<0.02$; second month: $\mathrm{F}_{1,16}=8.16, \quad P<0.02$; third month: $\mathrm{F}_{1,18}=5.37$, $P<0.05$; Fig. 6b). A busive mothers often restrained and rejected their infants in rapid succession in a way that was never observed among non-abusive mothers. The rate of maternal scratching when the infant was out of contact was higher for controls than for abusive mothers in the first month of life $\left(F_{1,7}=5.59, P=0.05 ; F\right.$ ig. 7). The rate of scratching also decreased more rapidly for 

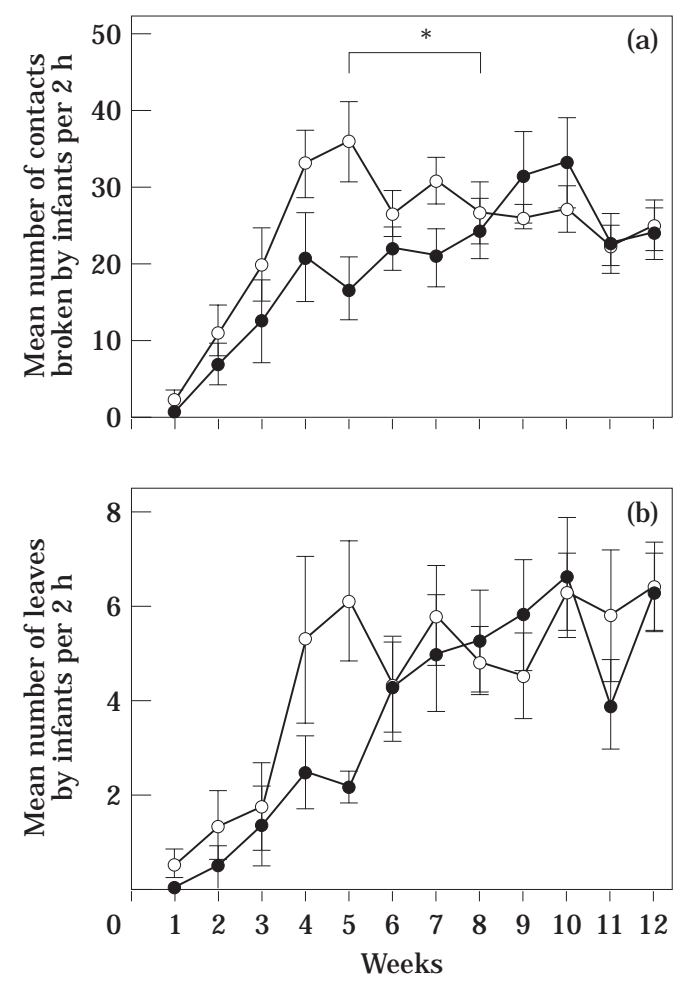

Figure 4. (a) $M$ ean \pm SE number of contacts broken by abused (- - ) and control (- - ) infants per individual per week. D ifferences are significant in the second month of infant life $(*)$; (b) mean \pm SE number of leaves by abused and control infants per individual per week.

controls than for abusive mothers in the first month $\left(\mathrm{F}_{3,21}=5.59, \mathrm{P}<0.01\right)$. In the third month, however, the rate of maternal scratching when the infant was out of contact was higher for abusive mothers than for controls $\left(F_{1,18}=9.04, P<0.01\right.$; Fig. 7)

\section{M other- 0 thers Interactions}

There were no significant differences in the frequency of contacts and approaches made by abusive and control mothers in any months (Table II). Abusive mothers received fewer contacts and approaches, however, from other individuals than controls (contacts, first month: $F_{1,15}=5.63$, $\mathrm{P}<0.05$; second month: $\mathrm{F}_{1,15}=4.86, \quad \mathrm{P}<0.05$; approaches, first month: $F_{1,15}=19.5, P=0.0005$; second month: $F_{1,16}=35.19, P<0.0001$; third month: $\left.F_{1,18}=10.85, P<0.005\right)$. There were no
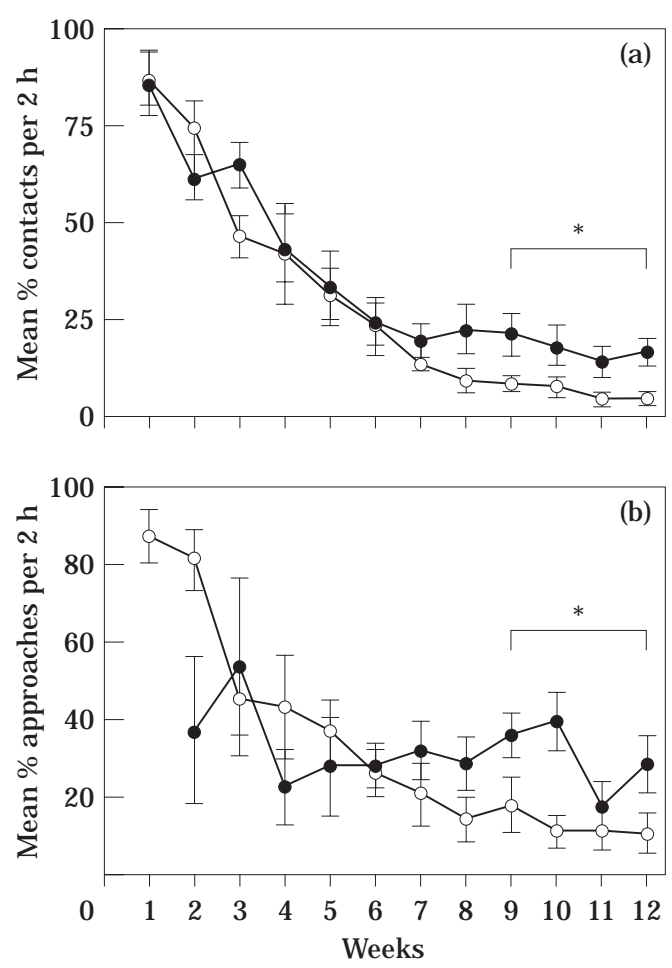

Figure 5. (a) $M$ ean \pm SE percentage of contacts made by abusive (- -$)$ and control ( $\bigcirc-)$ mothers per individual per week. Differences are significant in the third month of infant life $(*)$; (b) mean \pm se percentage of approaches made by abusive and control mothers per individual per week. Differences are significant in the third month of infant life $\left(^{*}\right)$.

significant differences between abusive mothers and controls in the frequency and duration of grooming done and received, except that the duration of grooming received was higher for abusive mothers than for controls in the third month $\left(F_{1,18}=5.02, P<0.05\right)$. The frequency of aggression received was not significantly different for abusive and control mothers, but abusive mothers were more aggressive than controls in the third month $\left(F_{1,18}=14.34, P=0.001\right)$. A busive mothers handled other infants significantly more frequently than controls in the third month $\left(F_{1,18}=4.41, P=0.05\right)$. All mothers increased the frequency with which they handled other infants as their own infants grew older (first month: $\mathrm{F}_{3,45}=4.58, \mathrm{P}<0.01$; second month: $\mathrm{F}_{3,48}=6.4, \mathrm{P}=0.001$; third month: $\left.F_{3,54}=5.44, P<0.01\right)$. 

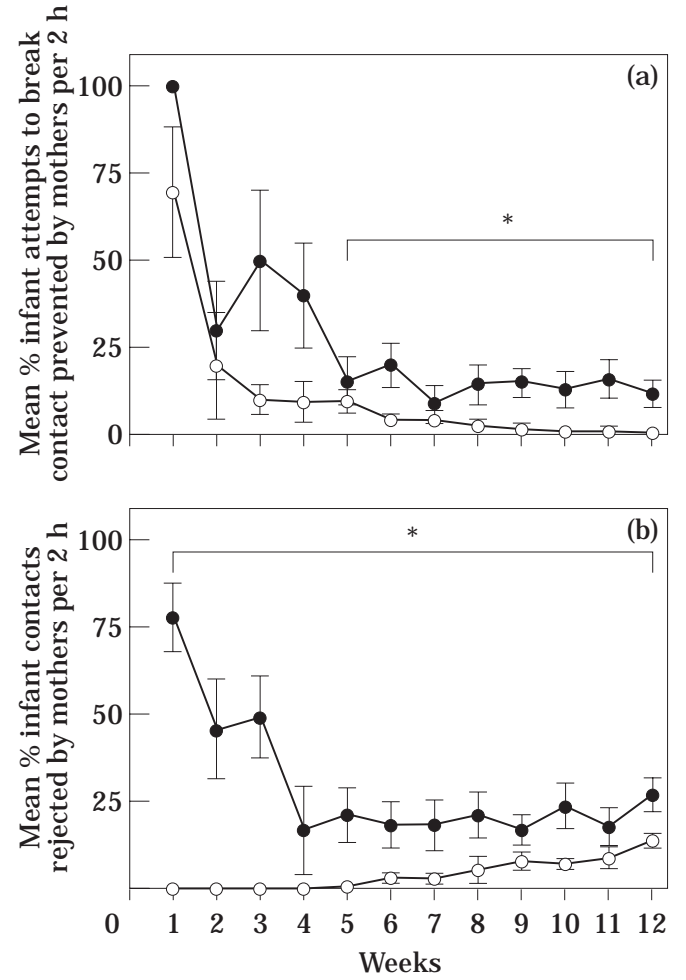

Figure 6. (a) M ean \pm SE percentage of infant attempts to break contact that were prevented by abusive (-0-) and control ( $-\bigcirc-$ ) mothers (restraining) per individual per week. Differences are significant in the second and third months of infant life $(*)$; (b) mean \pm SE percentage of infant attempts to make contact that were rejected by abusive and control mothers (rejection) per individual per week. Differences are significant in all 3 months of infant life $\left(^{*}\right)$.

\section{Infant- 0 thers Interactions}

A bused and control infants did not differ significantly in the frequency with which they were handled by other individuals in any month (Table II). A bused infants, however, were groomed more $\left(F_{1,15}=4.55, P=0.05\right)$ and harassed less by other individuals than controls in the first month $\left(F_{1,15}=15.25, P=0.001\right)$.

\section{DISC USSIO N}

The most frequent patterns of infant abuse in group-living rhesus macaques were infant dragging, crushing and throwing. A bused infants were

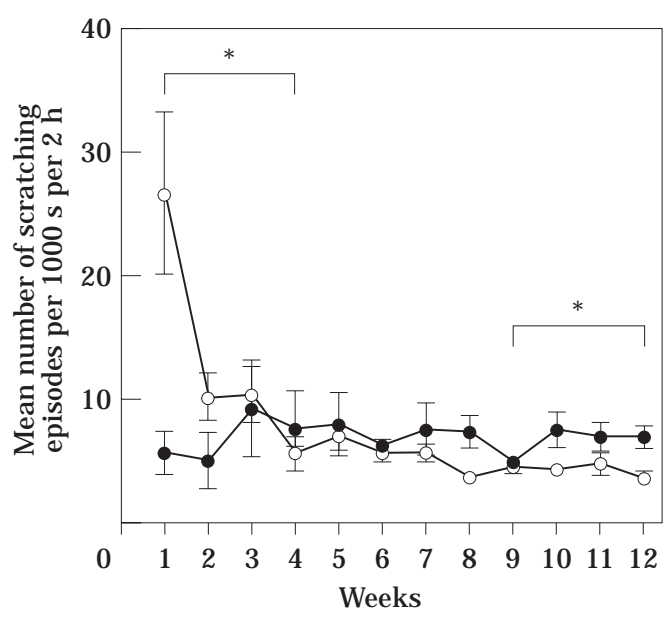

Figure 7. $M$ ean $\pm \mathrm{SE}$ rate of maternal scratching when the infant was out of contact per individual per week; $-\bigcirc-$, control; - - -, abuse. Differences are significant in the first and third months of infant life $\left(^{*}\right)$.

less frequently slapped or bitten by their mothers. Thus, during abuse events, rhesus infants were mostly treated by their mothers as though they were inanimate objects. This observation suggests that most infant abuse is qualitatively different from the aggressive behaviour that mothers use to encourage their infants' independence (Troisi \& D 'A mato 1983), although the two have often been confused (J ensen et al. 1969; Harlow 1974; N egayama 1981).

Although infant abuse in this study was never so severe as to require medical intervention, abused infants had higher basal concentrations of adrenocorticotrophin and cortisol than nonabused infants (D. M aestripieri \& P. Plotsky, unpublished data), suggesting that abuse had long-lasting stressful consequences. Other group members, notably juvenile and adult females, groomed abused infants more and harassed them less than non-abused infants in the first month, the period when abuse was most frequent. Although this finding could suggest empathy for abused infants, a more parsimonious explanation is that the behaviour was a response to the high frequency of their distress calls.

Since abuse does not appear likely to increase the infant's reproductive fitness, infant abuse falls outside the definition of parental care (CluttonBrock 1991). Infant abuse, however, could still be adaptive to the mother if abuse reflected a 
T able II. Social interactions between mothers, infants, and other individuals

\begin{tabular}{|c|c|c|c|c|c|c|}
\hline & \multicolumn{3}{|c|}{ A busive mothers } & \multicolumn{3}{|c|}{ Controls } \\
\hline & 1st month & 2nd month & 3rd month & 1st month & 2nd month & 3rd month \\
\hline \multicolumn{7}{|l|}{ M others-others } \\
\hline Contacts made & $3.7 \pm 0.6$ & $5.4 \pm 0.6$ & $4.8 \pm 0.5$ & $5.5 \pm 0.6$ & $5.8 \pm 0.5$ & $6.3 \pm 0.5$ \\
\hline Contacts received & $8.8 \pm 0.9 *$ & $8.1 \pm 0.7 *$ & $8.3 \pm 0.8$ & $14.0 \pm 0.8^{*}$ & $11.1 \pm 0.7^{*}$ & $9.0 \pm 0.6$ \\
\hline A pproaches made & $7.5 \pm 0.8$ & $10.3 \pm 0.9$ & $12.7 \pm 0.8$ & $7.8 \pm 0.6$ & $11.9 \pm 0.8$ & $12.3 \pm 0.8$ \\
\hline A pproaches received & $14.6 \pm 1.3^{*}$ & $13.4 \pm 1.0^{*}$ & $13.2 \pm 0.8^{*}$ & $25.0 \pm 1.5^{*}$ & $22.9 \pm 1.1^{*}$ & $19.0 \pm 0.9 *$ \\
\hline Grooming done $\mathrm{F}$ & $3.7 \pm 0.7$ & $4.8 \pm 0.6$ & $3.7 \pm 0.4$ & $5.9 \pm 0.7$ & $6.1 \pm 0.6$ & $6.1 \pm 0.7$ \\
\hline Grooming done $\mathrm{D}(\mathrm{s})$ & $588 \pm 114$ & $871 \pm 138$ & $703 \pm 105$ & $573 \pm 82$ & $716 \pm 88$ & $744 \pm 95$ \\
\hline Grooming received $\mathrm{F}$ & $5.0 \pm 0.8$ & $4.1 \pm 0.6$ & $4.7 \pm 0.6$ & $7.4 \pm 0.6$ & $5.2 \pm 0.6$ & $5.1 \pm 0.6$ \\
\hline Grooming received $D(s)$ & $672 \pm 140$ & $616 \pm 104$ & $962 \pm 140^{*}$ & $583 \pm 56$ & $469 \pm 47$ & $476 \pm 68^{*}$ \\
\hline A ggression done & $2.8 \pm 0.4$ & $2.9 \pm 0.5$ & $4.4 \pm 0.4^{*}$ & $2.6 \pm 0.4$ & $3.2 \pm 0.4$ & $2.2 \pm 0.3^{*}$ \\
\hline A ggression received & $1.3 \pm 0.2$ & $1.1 \pm 0.1$ & $1.4 \pm 0.2$ & $1.4 \pm 0.2$ & $1.6 \pm 0.2$ & $1.3 \pm 0.2$ \\
\hline Infant handling & $1.4 \pm 0.4$ & $4.9 \pm 0.7$ & $7.9 \pm 1.0^{*}$ & $0.9 \pm 0.2$ & $3.2 \pm 0.5$ & $4.9 \pm 0.5^{*}$ \\
\hline \multicolumn{7}{|l|}{ Infants-others } \\
\hline Infant handling & $8.3 \pm 1.3$ & $17.0 \pm 1.7$ & $13.5 \pm 1.1$ & $13.0 \pm 1.6$ & $23.4 \pm 2.0$ & $17.6 \pm 1.7$ \\
\hline Infant grooming (s) & $149 \pm 30^{*}$ & $54 \pm 15$ & $44 \pm 17$ & $66 \pm 14 *$ & $45 \pm 10$ & $19 \pm 5$ \\
\hline Infant harassment & $0.5 \pm 0.1^{*}$ & $1.5 \pm 0.4$ & $0.6 \pm 0.1$ & $1.6 \pm 0.3^{*}$ & $2.6 \pm 0.4$ & $1.6 \pm 0.5$ \\
\hline
\end{tabular}

$\mathrm{D}$ ata are presented as mean $\pm \mathrm{SE}$ values per individual per $2 \mathrm{~h}$ of observation.

$\mathrm{F}=$ frequency, $\mathrm{D}=$ duration. $* \mathrm{P} \leq 0.05$.

reduction or termination of parental expenditure in the offspring, and if the fitness benefits to the mother (increased chances of survival and future reproduction) outweighed the costs associated with loss of the current offspring. In contrast to this hypothesis, the present analysis of parenting styles suggests that abusive mothers invested more, not less, in their infants than did nonabusive mothers.

A busive mothers spent more time in contact with their infants than did non-abusive mothers in the second and third month of infant life. A busive mothers also restrained their infants more often in the second and third month and initiated a higher percentage of contacts and approaches with their infants than non-abusive mothers in the third month. These differences indicate that abusive mothers were generally more protective of their infants than non-abusive mothers. Abusive mothers rejected their infants more than nonabusive mothers in all three months and broke contact with their infants more than non-abusive mothers in the second month. Thus, abusive mothers were generally more rejecting than nonabusive mothers. Based on these differences in maternal behaviour, the parenting style of abusive mothers can be characterized as more controlling than that of non-abusive mothers (Fairbanks 1996).
The adaptive hypothesis of infant abuse predicts a rejecting or laissez-faire parenting style and not a controlling one. The hypothesis that infant abuse reflects an adaptive reduction of parental expenditure in the infant is inconsistent with the increased time spent in contact with infants and with the maternal protectiveness shown by abusive mothers. Increased mother-infant contact time observed among abusive mother-infant pairs probably resulted from infant as well as maternal behaviour. A bused infants attempted to break contact with their mothers less frequently than did non-abused infants in the first 2 months, probably as a result of the frequent abuse experienced in the first weeks. In fact, A rling \& Harlow (1967) showed that maternal abuse enhances infant clinging. The adaptive hypothesis also predicts an increase in the frequency of abuse with infant age and not a decrease, as observed in this study. Thus, the inconsistency between infant abuse and the parenting style of abusive mothers suggests that infant abuse is best viewed as a behavioural pathology ( $M$ aestripieri $\&$ Carroll, in press b).

A busive mothers were more aggressive towards other individuals than controls in the third month, suggesting that an aggressive temperament can perhaps contribute to the aetiology of infant abuse. Abusive mothers also received more grooming than controls during this period, but 
this may be an appeasement response to their increased aggressiveness. A busive mothers received fewer contacts and approaches from other individuals than controls, suggesting that they were avoided or feared by other individuals. Reduced social contact with other individuals may also contribute to the aetiology of infant abuse. Overall, however, the social behaviour of abusive mothers appeared to be well within the normal range for rhesus macaques, and infant abuse seems to be a pathology specific to the care-giving domain.

I propose several hypotheses concerning the mechanisms responsible for infant abuse. A busive mothers may have a general difficulty in responding adequately to the stimulus characteristics (visual, auditory, olfactory or tactile) of newborn infants, which are mostly behaviourally passive. This explanation is consistent with the early onset of infant abuse and maternal rejection observed in most mothers, but it is inconsistent with the strong interest shown by abusive mothers in the newborns of other females.

A Iternatively, abusive mothers may have an initial difficulty in forming a strong and specific bond with their infants. A busive mothers did not show the typical high frequency of scratching shown by macaque mothers upon interruption of contact with their infants in their first weeks of life, suggesting an initial lack of concern and anxiety over their infant's safety ( $M$ aestripieri 1993a, 1994b). A busive mothers, however, had higher scratching rates than controls in the third month. The hypothesis that abuse results from an initial difficulty in bonding with offspring does not account for the later onset of abuse observed in some cases and is inconsistent with the controlling parenting style of abusive mothers.

The parenting style of abusive mothers suggests another mechanism underlying abuse. Abusive mothers could be highly controlling individuals who use inadequate means for controlling their infant's behaviour (see also M aestripieri \& Carroll, in press $\mathrm{c}$ ). This hypothesis could account for the early onset of infant abuse because newborn infants are generally passive, and it is also consistent with the late onset of infant abuse if abuse is associated with significant changes in infant activity patterns. The use of abuse to control the infant's behaviour could be related to the temperament of abusive mothers (Troisi \& D'A mato 1994), could be learned through exposure to other abusive individuals, or both. Evidence of inter-generational transmission of infant abuse in monkeys ( $M$ aestripieri \& Carroll, in press a, $M$ aestripieri et al. 1997, in press) suggests that infant abuse could be transmitted from mothers to daughters with learning processes similar to those underlying the inter-generational transmission of parenting styles (F airbanks 1996).

Infant abuse may not be a unitary phenomenon, and the mechanisms responsible for its onset may be different from those underlying its maintenance or transmission across generations. Some of the characteristics of infant abuse in rhesus macaques may also be species-specific and related to other behavioural adaptations of this species. For example, the association between infant abuse and controlling parenting style suggests that infant abuse may be a by-product of selection for controlling parenting styles in rhesus macaques.

The need for protection of infants, coupled with the need to encourage early independence, is probably responsible for the controlling parenting style of rhesus mothers relative to some other macaque species (M aestripieri 1994b, c, 1995). Extreme levels of parental control, however, could increase the probability of occurrence of infant abuse, and rhesus females with the most controlling parenting styles could be especially at risk of displaying maladaptive behavior. A lthough the incidence of infant abuse in rhesus populations should be reduced by natural selection, the potential for maternal behaviour patterns to be transmitted across generations through experience and learning could contribute to the maintenance of this behavioural phenotype.

\section{ACKN O W LEDGMENTS}

This research was supported by grants from the Biomedical Resources Foundation (Houston, Texas), the Harry Frank Guggenheim Foundation ( $\mathrm{New}$ Y ork) and N IM H (R 03-M H 56328) to $D$. M aestripieri and in part by $\mathrm{NIH}$ grant RR-00165 to the Yerkes Regional Primate Research Center. The Y erkes Center is fully accredited by the American Association for Accreditation of Laboratory A nimal Care. I thank K elly Carroll, Lynn Fairbanks and K im W allen for comments on the paper. A Ifonso Troisi and $F$ rancesca D 'A mato deserve credit for many ideas expressed in this paper. 


\section{REFERENCES}

A rling, G. L. \& H arlow, H. F. 1967. Effects of social deprivation on maternal behavior of rhesus monkeys. J . comp. Physiol. P sychol., 64, 371-377.

Bernds, W. P. \& Barash, D. P. 1979. Early termination of parental investment in mammals, including humans. In: Evolutionary Biology and Human Social Behavior (Ed. by N. A. Chagnon \& W. Irons), pp. 487-506. N orth Scituate, M assachusetts: D uxbury.

Brown, J. R., Ye, H., Bronson, R. T., Dikkes, P. \& Greenberg, M . E. 1996. A defect in nurturing in mice lacking the immediate early gene fosB. C ell, 86, 297309.

Clutton-Brock, T. H. 1991. The Evolution of Parental Care. Princeton, New Jersey: Princeton U niversity Press.

Daly, M.\& Wilson, M. I. 1981. A buse and neglect of children in evolutionary perspective. In: Natural Selection and Social Behavior (Ed. by R. D. A lexander \& D. W. Tinkle), pp. 404-416. N ew York: Chiron Press.

F airbanks, L. A. 1996. Individual differences in maternal styles: causes and consequences for mothers and offspring. Adv. Study B ehav., 25, 579-611.

Fairbanks, L. A . \& M CG uire, M. T. 1995. M aternal condition and the quality of maternal care in vervet monkeys. Behaviour, 132, 733-754.

Haig, D. 1990. Brood reduction and optimal parental investment when offspring differ in quality. A m. N at., 136, 550-566.

Harlow, H. F. 1974. L earning to L ove. N ew Y ork: J ason A ronson.

H arlow, H . F . \& Seay, B. 1966. M othering in motherless mother monkeys. Br. J. Soc. P sychiat., 1, 63-69.

H iraiwa, M. 1981. M aternal and alloparental care in a troop of free-ranging Japanese monkeys. Primates, 22, 309-329.

Jensen, G. D., Bobbitt, R. A. \& Gordon, B. N. 1969. Patterns and sequences of hitting behavior in mother and infant monkeys (M acaca nemestrina). J. Psychiatr. R es., 7, 55-61.

$M$ aestripieri, D. 1991. Litter gender composition, food availability, and maternal defence of the young in house mice (M us domesticus). Behaviour, 116, 139151.

M aestripieri, D. 1993a. M aternal anxiety in rhesus macaques (M acaca mulatta). I. M easurement of anxiety and identification of anxiety-eliciting situations. Ethology, 95, 19-31.

M aestripieri, D. 1993b. M aternal anxiety in rhesus macaques (M acaca mulatta). II. Emotional bases of individual differences in mothering style. E thology, 95, 32-42.

M aestripieri, D. 1994a. Infant abuse associated with psychosocial stress in a group-living pigtail macaque (M acaca nemestrina) mother. Am. J. Primatol., 32, 41-49.
M aestripieri, D. 1994b. M other-infant relationships in three species of macaques ( $\mathrm{M}$ acaca mulatta, $M$. nemestrina, $M$. arctoides). I. D evelopment of the mother-infant relationship in the first three months. Behaviour, 131, 75-96.

M aestripieri, D. 1994c. M other-infant relationships in three species of macaques ( $\mathrm{M}$ acaca mulatta, $M$. nemestrina, $M$. arctoides). II. The social environment. Behaviour, 131, 97-113.

M aestripieri, D. 1995. First steps in the macaque world: do rhesus mothers encourage their infants' independent locomotion? A nim. B ehav., 49, 1541-1549.

M aestripieri, D . \& Carroll, K . A . In press a. R isk factors for infant abuse and neglect in group-living rhesus monkeys. P sychol. Sci.

M aestripieri, D . \& Carroll, K . A . In press b. Child abuse and neglect: usefulness of the animal data. Psychol. Bull.

M aestripieri, D. \& Carroll, K. A. In press C. Behavioral and environmental correlates of infant abuse in group-living pigtail macaques. Inf. B ehav. Dev.

M aestripieri, D., Wallen, K. \& Carroll, K. A. 1997. Infant abuse runs in families of group-living pigtail macaques. Child A buse N egl. 21, 465-471.

M aestripieri, D., Wallen, K. \& Carroll, K. A. In press. $G$ enealogical and demographic influences on infant abuse and neglect in group-living sooty mangabeys (Cercocebus atys). D evl P sychobiol.

M aestripieri, D., Schino, G., A ureli, F.\& Troisi, A. 1992. A modest proposal: displacement activities as an indicator of emotions in primates. Anim. Behav., 44, 967-979.

M artin, P. \& Bateson, P. 1986. M easuring B ehaviour. A n Introductory Guide. Cambridge: Cambridge University Press.

N egayama, K . 1981. M aternal aggression to its offspring in J apanese macaques. J. H um. E vol., 10, 523-527.

Trivers, R. L. 1972. Parental investment and sexual selection. In: Sexual Selection and the D escent of $M$ an (Ed. by B. Campbell), pp. 136-179. Chicago: Aldine.

Troisi, A . \& D 'A mato, F. R. 1983. Is monkey maternal abuse of offspring aggressive behavior? Aggress. B ehav., 9, 167-173.

Troisi, A. \& D'A mato, F. R. 1994. M echanisms of primate infant abuse: the maternal anxiety hypothesis. In: Infanticide and Parental Care (Ed. by $\mathrm{S}$. Parmigiani \& F. vom Saal), pp. 199-210. London: Harwood.

Troisi, A., D 'A mato, F. R., Fuccillo, R. \& Scucchi, S. 1982. Infant abuse by a wild-born group-living J apanese macaque mother. J. abnorm. Psychol., 91, 451-456.

Williams, G. C. 1966. N atural selection, the costs of reproduction, and a refinement of Lack's principle. A m. N at., 100, 687-690.

W inkler, D. W. 1987. A general model for parental care. A m. N at., 130, 526-543. 